\title{
Jacqui Briggs EPS Prize 2020
}

(c) European Consortium for Political Research 2021

Congratulations to the winning article of the Jacqui Briggs EPS Prize 2020. TuuliMarja Kleiner for the article "Does Ideological Polarisation Mobilise Citizens?" (EPS, Vol. 19, No. 4, 2020)

In their assessment the judges summarized the benefits of the article as follows:

"The article makes an important contribution to an emerging field of study. The author uses subnational European data on voting and non-voting participation to see if increases in polarization induce higher levels of political engagements. Although there are countless examples of entrenched political polarization, political scientists have only begun to seek an adequate understanding of how this affects citizens' engagement with politics. The author finds that political-party polarization does produce more non-electoral engagement by citizens but does not lead to higher levels of turnout at the polls. The effect is mostly driven by those with far-right views. The analysis is well done, and it acts as a solid starting point for future research. The focus on non-electoral participation confirms other work showing its importance to the development of populist movements."

The prize committee was comprised of:

Susan Rose-Ackerman, Yale University (chair),

Ben Rosamond, University of Copenhagen

Stuart A. Brown, London School of Economics

Publisher's Note Springer Nature remains neutral with regard to jurisdictional claims in published maps and institutional affiliations. 